\title{
Combined Economic Emission Dispatch- Pareto Optimal Front Approach
}

\author{
K.Vinod Kumar \\ Department of Electrical Engineering \\ National Institute of Technology \\ Warangal
}

\author{
G.Lakshmi Phani \\ Department of Electrical Engineering \\ National Institute of Technology \\ Warangal
}

\begin{abstract}
Recent advancements in artificial intelligence especially in evolutionary algorithms have enabled much efficient way to solve the constrained optimization problems in various fields of engineering. In this paper we explain the development of the optimization techniques from single criterion to multi criterion. We also address the Combined Economic and Emissions Dispatch (CEED) problem in thermal power stations. We use the aggregate objective function approach to solve the multiobjective CEEED problem using firefly optimization technique. Then we simulate the proposed approach on a test system and formulate the pareto optimal front for three different load demands. This proves that the algorithm can be effectively used to solve such multiobjective problems.
\end{abstract}

\section{General Terms}

Nature Inspired Computing Techniques, Economic Load dispatch, Combined Economic Emission Dispatch, Evolutionary Algorithms, Artificial Intelligence.

\section{Keywords}

Combined Economic Emission Dispatch, Firefly Optimization Algorithm, Green House Effect, Economic Load Dispatch, Nature Inspired Algorithms.

\section{INTRODUCTION}

The growth of technology has extended the boundaries of science and logic to a greater domain. Especially power generation has seen many developments and still continues to attract researchers. Technology enabled us to generate and transmit power from one place to another but engineering can enable to transmit this power with least expense. The demand is not met by a single generating unit. Many generating units share the load and thus the total generation capacity is thus achieved by the individual generations put together. The concept of economic dispatch suggests that this distribution among the different units can be done such that the total cost of production is minimized.

The rising concentrations of green house gases (GHGs) of anthropogenic origin in the atmosphere such as Carbon Dioxide $\left(\mathrm{CO}_{2}\right)$, Methane $\left(\mathrm{CH}_{4}\right)$, and Nitrous Oxide $\left(\mathrm{N}_{2} \mathrm{O}\right)$ have increased, since the late $19^{\text {th }}$ century. According to the Third Assessment Report (TAR) of the inter government Panel on climatic changes, because of increase in the concentration of the green house gases in the atmosphere in the last 100 years, the mean surface temperature has risen by $0.4-0.8^{0} \mathrm{C}$ globally. The precipitation has become spatially variable and the intensity and frequency of extreme events has increased. The sea level has also risen at an average rate of 1-2 mm during this period. This continuous increase in the concentration of the green house gases will result in more severe changes in the eco system and may cause imbalance in the nature. In this industrial era, many activities of the man emit the green house gases into the atmosphere, mainly through burning fossil fuels and deforestation. The carbon dioxide emissions by burning of fossil fuels can be classified into seven categories namely, Solid fuels $35 \%$, liquid fuels $36 \%$, gaseous fuels $20 \%$, flaring gas $<1 \%$, cement production $3 \%$, non-fuel hydrocarbons $<1 \%$, the international bunkers of shipping and air transport 4\%. To minimize these emission researchers have proposed solutions that use the artificial intelligence techniques.

In [1] Authors solved emission constrained economic dispatch problem using Fuzzy Guided Tabu Search (FGTS). The problem is formulated as a multi-objective function. Results of 6-unit system with FGTS are compared with Tabu Search and analytical methods. In [2] taking emission constrained economic dispatch as multi-objective function, results are obtained on a 30-bus standard test system using PSO. No comparision with any other optimization technique. In paper [3] modelling of machines to suit our constraints was discussed. Ideas were proposed. No optimization technique. Results using lambda iteration technique are given. Authors in [4] Common Emission and economic dispatch problem is considered and evaluated using Particle Swarm Optimization(PSO), Dispersed Particle Swarm Optimization (DPSO), New Particle Swarm Optimization (NPSO). The authors stressed on the description of the algorithms and concluded saying it is better to conventional Genetic Algorithm(GA). The paper [5] develops a lambda based-GA approach to solve the ED problem taking emission constraints into account. Here losses are also considered and in the generation constraint for a generation of $300 \mathrm{MW}, 1 \%$ error was taken as acceptable. In [6] solution for common emission and economic dispatch problem through sequential approach with matrix framework considering all constraints. Results were shown for a 10 generator system with multiple fuel options. The paper [7] proposes to solve the multi-objective problem of emission constrained economic dispatch using Improved Genetic Algorithm. Three different examples were taken and the results were compared with two other methods: Linear Programming and Genetic Algorithm method. [8] BBBC algorithm has been tested with the IEEE 30-bus system with different fuel cost characteristics, quadratic cost curve model, and quadratic cost curve with valve-point effects model. In [9] a new optimization technique called the BB-BC has been proposed by the authors. Genetic algorithm and Simulated Annealing have been discussed and the superiority of the 
proposed method over these two is shown in the results. The authors in [10] discussed "Big Crunch" Optimization technique which is similar to BBBC. Results of present algorithm are compared with other algorithms like GA.

\section{MULTIOBJECTIVE OPTIMIZATION}

The The pioneer work of Rosenberg in late 60's regarding the possibility of using genetic algorithm based search to deal with multiple objectives laid the foundations for a very important area in the research called "Multiobjective Optimization." This area of research has gained a lot of importance in past 15 years. Many researchers and scientists have proposed many techniques and methodologies in peer-reviewed journals and international conferences across the globe. Multiobjective Optimization is an important area of research for both engineers and scientists. This is because all the real world problem are never simple and they involve in multiple criterions to be fulfilled by the proposed solution. [15] [16] [17].

Multiobjective optimization (also called as multicriterion optimization, multiperformance or vector optimization) can be defined as the problem of finding a vector of decision variables which satisfies a set of constraints (if any exist) and optimizes a vector function whose elements represents multiple objectives. These objectives are the mathematical description of different performance indices of a given system. In many real time problems the objectives are often in conflict with each other. This means betterment of an individual objective may worsen the other. This is the reason we call this as optimizing the multiple objectives of a system. The problem can be formally stated as below:

The vector solution that we need to find is:

$$
x^{*}=\left[x_{1}^{*}, x_{2}^{*}, \ldots \ldots \ldots \ldots x_{n}^{*}\right] T
$$

Then we also have $\mathrm{p}$ equality and $\mathrm{m}$ inequality constraints:

$$
\begin{aligned}
& \max >g_{i}(x)>\min \quad i=1,2 \ldots . m \\
& h_{i}(x)=\text { constant } \quad i=1,2 \ldots \ldots p
\end{aligned}
$$

This is the vector function with $\mathrm{k}$ objectives that we need to optimize satisfying the above mentioned constraints:

$$
f(x)=[f 1(x), f 2(x), f 3(x), \ldots \ldots \ldots f k(x)] T
$$

In other words the main aim is to find the vector $x^{*}$ satisfying the constraints (1) and (2) there by optimizing all the objectives of the vector function (3).

The concept of pareto optimum and pareto front:

The concept of pareto optimum was formulated by Vilfredo Pareto. We can say that a point $x^{*} € F$ either,

$$
\left(f i(x)=f i\left(x^{*}\right)\right) \quad \text { for } \mathrm{i} € \mathrm{I}
$$

or, there is at least one $\mathrm{i} € \mathrm{I}$ such that

$$
f i(x)>f i\left(x^{*}\right)
$$

In other words, $x^{*}$ is said to be Pareto Optimal if there exists no feasible vector $\mathrm{x}$ which would decrease some criterion without causing a simultaneous increase in a tleast one other criterion. But in most of the cases, Pareto Optimum is not a single solution, rather a set of solutions called as non dominated solutions.

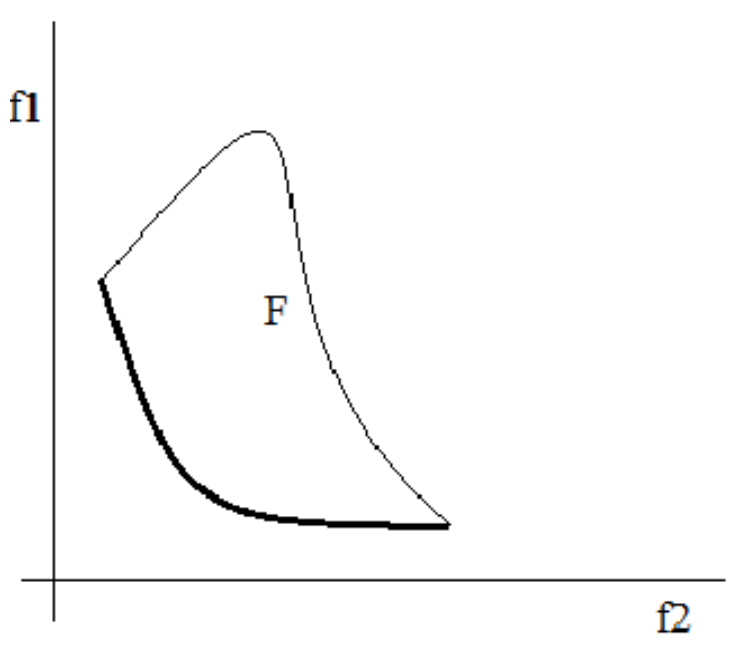

Fig 1: Pareto Optimal Front

The region of points defined by a bold line is called as a Pareto Front. In general it is very difficult to find an analytical expression of the line or surface that contains these points

The Aggregating Function approach to solve multiobjective or multicriterion functions is very simple and efficient. Here there is no need of further interaction with the decision maker. The approach of combining different objectives into a single objective has been attempted several times in the literature with relative success. The only limitation with this method is the decision maker should have prior knowledge on each of the criterion

1. Weighted Sum Approach

2. Goal Programming

3. e- constrained method.

Among all these methods the Weighted Sum Approach is most efficient and simple method. Weighted Sum Approach: In this method, different objectives are added up with different weights to form a single objective function. This can be solved using the same methods that we adopt to solve single objective functions.

$$
\min \sum_{i=1}^{k} w i f i(x)
$$

Where $\mathrm{w} i>=0$ are the weighing coefficients representing the relative importance of the objectives. It is usually assumed that

$$
\sum_{i=1}^{k} w i=1
$$

In this case the designer must be aware of deciding the weights of each of the $\mathrm{k}$ objectives. For this the designer must be aware of all the objectives. Jakob et al. used a weighted sum approach in a task planning problem: to move the tool centre point of an industrial robot to a location as precise as possible avoiding certain obstacles aiming the path to be as smooth as possible and 
as short as possible. Yang and Gen [20] used a weighted sum approach to solve a bicriteria linear transportation problem. Gen et al. $[18,19]$ extended this approach to allow more than two objectives, and added a additional feature i.e, fuzzy logic to make decision upon the weights.

With the rising demand, the generation cannot be increased as the emissions must be taken into account. Thermal power plants

\section{PROBLEM FORMULATION}

The problem formulation is discussed in this section.

\subsection{Economic Dispatch Problem}

Power sector is aimed at producing good quality power at the minimum feasible cost. Any power plant has a running cost apart from the usual initial cost of establishment. Especially in thermal power plants which contribute to the major share of power generation the cost of coal is high unlike other renewable source based like hydro power. The cost of generation directly affects the price paid by consumer for the utility. Hence many techniques have been discovered to keep this cost of generation to the minimum.

The load is shared by many generating units which are in parallel operation. When the demand is very high or during the peak times, it would be necessary to avail the full generation capacity of a power plant. However, if the total capacity of generation is not necessary, those generators which have been found to have lower cost of production can be engaged. The concept of economic dispatch problem can be defined by

Minimize $\mathrm{Ft}=\sum \mathrm{Fi}(\mathrm{Pi}) \mathrm{Rs} / \mathrm{hr}$

The fuel cost function is generally described by a quadratic equation of power output $\mathrm{Pi}$ as :

$\mathrm{Fi}(\mathrm{Pi})=\mathrm{ai} \mathrm{Pi}^{2}+\mathrm{bi} \mathrm{Pi}+\mathrm{ci} \quad \mathrm{Rs} / \mathrm{hr}$

Where $\mathrm{Pi}$ is the power output by the i'th generator and ai bi and ci are the cost constraints of the i'th generator.

\subsection{Emissions Problem}

Global warming is the one of the most pressing problems of today's world which has arisen in the face of growing technology. The weight of this problem of global warming or else rise of global temperatures is clear as it questions the fate of the earth to a probable premature end. Geologists say that unless the carbon dioxide emissions are not controlled, the global changes in climate and sea levels would reach an alarming level where it will not be possible for the nature to heal itself.

Geologists predict that human geological footprint will be visible in a variety of areas, one of them being contributing to increased $\mathrm{CO}_{2}$ levels. Humans have raised this level by $40 \%$ since the Industrial revolution and this may double or triple it over the coming century. . Major sources of $\mathrm{CO}_{2}$ in the atmosphere are emissions from the power plants. Thermal power plants are the major sources of power in many countries. Recent studies suggest that limiting the emissions into the nature would be a significant advance towards its rehabilitation process. Limiting emissions should be achieved without limiting the power generation. It is therefore, essential to go for a generation technique which satisfies both the constraints. Therefore, we formulate the problem that we need to reduce emissions without compromising with the generation.

An emission problem can be considered similar to economic dispatch problem in the sense that in both the cases the minimizing function is similar. The emission equation for a generating unit is given by:

$$
\mathrm{E}_{\mathrm{i}}=\mathrm{d}_{\mathrm{i}} \mathrm{P}_{\mathrm{i}}^{2}+\mathrm{e}_{\mathrm{i}} \mathrm{P}_{\mathrm{i}}+\mathrm{f}_{\mathrm{i}} \quad \mathrm{kg} / \mathrm{hr}
$$

Where $d_{i} e_{i} f_{i}$ are the emission coefficients of a unit $i$.

\subsection{Combined Economic Emissions Dispatch}

The total generation must supply the online demand.

Economic dispatch problem and emission problem were treated as different problems until a long time earlier. Emission constrained economic dispatch was developed in a different technique by Granelli et al[1]. The author has reduced the economic emission dispatch problem into a single objective one by treating the emission as a constraint. Better results which are compatible with the constraints and which satisfy both the emission and economic dispatch part of the problem were sought for. Thereafter many researchers have proposed various methods to solve the combined economic and emission problem. In a research direction, the multi-objective CEED problem was converted into a single objective problem by linear combination of different objectives as a weighted sum[12-14]. Farag et al[15] has proposed a linear programming based optimization method in which the objectives are considered separately one at a time. Here we first define the CEED problem and the constraints and propose to solve it by the Big Bang Big Crunch Algorithm. The CEED problem can be formulated as follows

$\mathrm{Fi}(\mathrm{Pi})=\left(\mathrm{ai} \mathrm{Pi}^{2}+\mathrm{bi} \mathrm{Pi}+\mathrm{ci}\right)+\mathrm{hi}\left(\mathrm{di} \mathrm{Pi}^{2}+\mathrm{ei} \mathrm{Pi}+\mathrm{fi}\right) \quad \mathrm{Rs} / \mathrm{hr}$

Where hi is called the penalty factor hi $=$ Fi max / Ei max

$\begin{array}{ll}\text { Fi max }=\text { ai } \mathrm{Pi}^{2} \max +\text { bi Pi } \max +\text { ci } & \mathrm{Rs} / \mathrm{hr} \\ \text { Ei max }=\text { di } \mathrm{Pi}^{2} \max +\text { ei Pi max + fi } & \mathrm{Kg} / \mathrm{hr}\end{array}$

\subsection{Generator Limit Constraints}

There will be some upper and lower limits for any generating unit. The power generation of unit $\mathrm{n}$ should be in between its minimum and maximum limits only.

$\mathrm{P}_{\mathrm{n}} \min <\mathrm{P}_{\mathrm{n}}<\mathrm{P}_{\mathrm{n}} \max$

where

$\mathrm{P}_{\mathrm{n}}$ min is the minimum limit of unit $\mathrm{n}$

$\mathrm{P}_{\mathrm{n}}$ max is the maximum limit of unit $\mathrm{n}$.

\subsection{Power Balance Constraints}

The total generation must meet the demand

$\sum(\mathrm{Pi})=\mathrm{Pd}$

Where $\mathrm{Pd}$ is load demand and $\mathrm{Pi}$ is the generation of the $\mathrm{i}$ 'th unit.

\section{FIREFLY OPTIMIZATION TECHNIQUE}

The Fire Fly Optimization Algorithm is based on the biochemical and social behaviour of the fireflies. Fireflies produce 
luminescent flashes as a signal system to communicate with other fireflies, especially to prey attractions. The algorithm has 4 main assumptions. They are:

1. All the fire flies are unisexual, means there are no male and female fire flies as such.

2. Every fire fly communicates with the other flies using the luminous flashes.

3. The attraction is directly proportional to the brightness of the light that the fly emits and which is inversely proportional to the distance between them.

4. No fire fly can attract the brightest fire fly and in fact all the others are attracted to the brightest one.

In this algorithm all the fire flies initially will be at random locations in the search space. Based on the fitness values they produce the light with certain intensity proportional to its fitness. All the fireflies move towards the brighter fire fly and eventually an optimum solution is found in the search space.

The pseudo code for the Fire fly optimization algorithm is as follows:

Input :

$\mathrm{F}(\mathrm{n}), \mathrm{n}=[\mathrm{n} 1, \mathrm{n} 2, \mathrm{n} 3, \ldots \ldots \ldots .$.$] \quad objective function \}$

$\mathrm{S}=\left[\mathrm{a}_{\mathrm{k}}, \mathrm{b}_{\mathrm{k}}\right]$ for all $\mathrm{k}=1,2,3, \ldots \ldots, \mathrm{n}\{$ constraints of the problem $\}$

$\mathrm{F}, \mathrm{G}, \mathrm{B}, \max _{\mathrm{i}}, \min _{\mathrm{i}} \quad$ \{ Algorithm inputs \}

Output:

$\mathrm{X}_{\mathrm{i} \text { min }} \quad$ \{Resultant global minima point $\}$

Begin;

For $\mathrm{i}=1$ to $\mathrm{F}$

$\mathrm{X}(\mathrm{i})=>$ Initialize the positions of the flies

End

Repeat

Begin

i $\min <=\arg \min _{\mathrm{i}} \mathrm{f}\left(\mathrm{x}_{\mathrm{i}}\right)$

$\mathrm{Xi} \min <=\arg \min _{\mathrm{xi}} \mathrm{f}\left(\mathrm{x}_{\mathrm{i}}\right)$

For $\mathrm{i}=1$ to $\mathrm{m}$ do

For $\mathrm{j}=1$ to $\mathrm{m}$ do

If $\mathrm{f}\left(\mathrm{x}_{\mathrm{j}}\right)<\mathrm{f}\left(\mathrm{x}_{\mathrm{i}}\right)$ then $\{$ move firefly $\mathrm{i}$ towards $\}$

$\mathrm{r}_{\mathrm{j}}<=$ calculate distance $\left(\mathrm{x}_{\mathrm{i}}, \mathrm{X}_{\mathrm{j}}\right)$

$\mathrm{B}<=\mathrm{B}_{\mathrm{o}} \mathrm{e}^{-\mathrm{Gr}}\{$ obtain attractiveness $\}$

$\mathrm{U}_{\mathrm{i}}<=$ Generate Random Vector $\left\{\min \mathrm{u}_{\mathrm{i}}\right.$,

$\left.\max u_{i}\right\}$

For $\mathrm{k}=1$ to $\mathrm{n}$ do

$\mathrm{X}$ i min, $\mathrm{k}<=\mathrm{X}$ i min, $\mathrm{k}+\mathrm{U}$ i min, $\mathrm{k}$

End

End
End

End

$\mathrm{U}$ i min $<=$ Generate Random Vector $\left\{\min \mathrm{u}_{\mathrm{i}}, \max \mathrm{u}_{\mathrm{i}}\right\}$

For $\mathrm{k}=1$ to $\mathrm{n}$ do

$$
\mathrm{Xi} \min , \mathrm{k}<=\mathrm{Xi} \min , \mathrm{k}+\mathrm{U} \mathrm{I} \min , \mathrm{k}
$$

\{best firefly should move randomly \}

End

Until stop condition true

End

\section{TEST SYSTEM}

The parameters of the test system are noted in this section. Table 1 gives the emission coefficients of the 6 generator test system. Table 2 gives the cost coefficients of the 6 generator system. The power limits of the individual generators is also noted.

\begin{tabular}{|l|l|l|l|l|l|}
\hline Generator & $\mathrm{d}_{\mathrm{i}}$ & $\mathrm{e}_{\mathrm{i}}$ & $\mathrm{f}_{\mathrm{i}}$ & Pmin & Pmax \\
\hline Unit 1 & 0.0042 & 0.3300 & 13.86 & 50 & 200 \\
\hline Unit 2 & 0.0042 & 0.3300 & 13.86 & 20 & 80 \\
\hline Unit 3 & 0.0068 & -0.5455 & 40.26 & 15 & 50 \\
\hline Unit 4 & 0.0068 & -0.5455 & 40.26 & 10 & 35 \\
\hline Unit 5 & 0.0046 & -0.5112 & 42.96 & 10 & 30 \\
\hline Unit 6 & 0.0046 & -0.5112 & 42.96 & 12 & 40 \\
\hline
\end{tabular}

Table 1. Emission Coefficients of test system

\begin{tabular}{|l|l|l|l|l|l|}
\hline Generator & $\mathrm{a}_{\mathrm{i}}$ & $\mathrm{b}_{\mathrm{i}}$ & $\mathrm{c}_{\mathrm{i}}$ & Pmin & Pmax \\
\hline Unit 1 & 0.0000 & 2.0000 & 0.00376 & 50 & 200 \\
\hline Unit 2 & 0.0000 & 1.7500 & 0.01750 & 20 & 80 \\
\hline Unit 3 & 0.0000 & 3.0000 & 0.25000 & 15 & 50 \\
\hline Unit 4 & 0.0000 & 1.0000 & 0.06250 & 10 & 35 \\
\hline Unit 5 & 0.0000 & 3.2500 & 0.00834 & 10 & 30 \\
\hline Unit 6 & 0.0000 & 3.0000 & 0.02500 & 12 & 40 \\
\hline
\end{tabular}

Table 2. Cost Coefficients of test system

\section{SIMULATION AND EVALUATION}

The simulations are carried out on MATLAB software. The processor is intel core2duo. We have varied the weights of the emissions and the cost objective ranging from 0 to 1 . Thus plotting these values gives us the pareto optimal front for a given load. We found pareto optimal fronts for three different load conditions. 


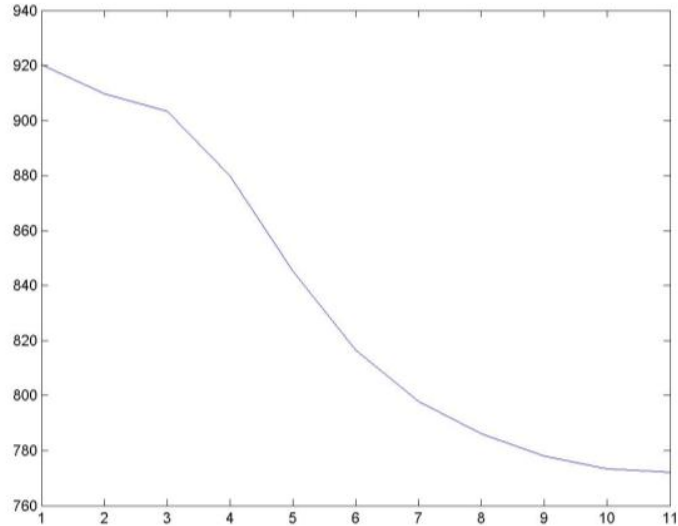

Fig 1: Pareto Optimal Front for the demand 284.3MW

\begin{tabular}{|l|l|l|l|}
\hline $\begin{array}{l}\text { Weight } \\
\text { of cost }\end{array}$ & $\begin{array}{l}\text { Weight of } \\
\text { emission }\end{array}$ & $\begin{array}{l}\text { Total } \\
\text { Cost }\end{array}$ & $\begin{array}{l}\text { Total } \\
\text { Emissions }\end{array}$ \\
\hline 1.0 & 0.0 & 509.1242 & 280.3798 \\
\hline 0.9 & 0.1 & 509.3038 & 277.2895 \\
\hline 0.8 & 0.2 & 509.9213 & 273.8298 \\
\hline 0.7 & 0.3 & 512.9255 & 265.6855 \\
\hline 0.6 & 0.4 & 523.2255 & 246.8584 \\
\hline 0.5 & 0.5 & 540.2725 & 226.0715 \\
\hline 0.4 & 0.6 & 561.0268 & 209.2279 \\
\hline 0.3 & 0.7 & 593.9086 & 191.7208 \\
\hline 0.2 & 0.8 & 614.2194 & 184.7513 \\
\hline 0.1 & 0.9 & 614.5367 & 184.6988 \\
\hline 0.0 & 1.0 & 615.1523 & 184.6661 \\
\hline
\end{tabular}

Table3. Cost \& Emissions for different weights at $200 \mathrm{MW}$

\begin{tabular}{|l|l|l|l|}
\hline $\begin{array}{l}\text { Weight } \\
\text { of cost }\end{array}$ & $\begin{array}{l}\text { Weight of } \\
\text { emission }\end{array}$ & $\begin{array}{l}\text { Total } \\
\text { Cost }\end{array}$ & $\begin{array}{l}\text { Total } \\
\text { Emissions }\end{array}$ \\
\hline 1.0 & 0.0 & 772.1992 & 393.0727 \\
\hline 0.9 & 0.1 & 773.4317 & 373.5184 \\
\hline 0.8 & 0.2 & 778.1355 & 347.4318 \\
\hline 0.7 & 0.3 & 786.2031 & 322.9253 \\
\hline
\end{tabular}

\begin{tabular}{|l|l|l|l|}
\hline 0.6 & 0.4 & 797.9756 & 301.2266 \\
\hline 0.5 & 0.5 & 816.5608 & 278.6538 \\
\hline 0.4 & 0.6 & 845.2753 & 255.3466 \\
\hline 0.3 & 0.7 & 879.9038 & 236.5295 \\
\hline 0.2 & 0.8 & 903.2392 & 228.2421 \\
\hline 0.1 & 0.9 & 909.6543 & 227.1378 \\
\hline 0.0 & 1.0 & 920.3592 & 226.6148 \\
\hline
\end{tabular}

Table 2. Cost \& Emissions for different weights at 283.4MW

\begin{tabular}{|l|l|l|l|}
\hline $\begin{array}{l}\text { Weight } \\
\text { of cost }\end{array}$ & $\begin{array}{l}\text { Weight of } \\
\text { emission }\end{array}$ & $\begin{array}{l}\text { Total } \\
\text { Cost }\end{array}$ & $\begin{array}{l}\text { Total } \\
\text { Emissions }\end{array}$ \\
\hline 1.0 & 0.0 & 1218.4 & 438.3280 \\
\hline 0.9 & 0.1 & 1218.6 & 435.6726 \\
\hline 0.8 & 0.2 & 1219.1 & 432.6151 \\
\hline 0.7 & 0.3 & 1220.3 & 429.0599 \\
\hline 0.6 & 0.4 & 1227.5 & 417.0688 \\
\hline 0.5 & 0.5 & 1249.3 & 390.2530 \\
\hline 0.4 & 0.6 & 1269.1 & 373.5278 \\
\hline 0.3 & 0.7 & 1273.4 & 370.9134 \\
\hline 0.2 & 0.8 & 1273.4 & 370.9123 \\
\hline 0.1 & 0.9 & 1273.4 & 370.9123 \\
\hline 0.0 & 1.0 & 1273.4 & 370.9123 \\
\hline$T$ & & & \\
\hline
\end{tabular}

Table 3. Cost \& Emissions for different weights at 200MW

These tables show that the optimal operating points in a multiobejective problem form a smooth surface. We plotted the surface for a load of 284.3 MW in figure 2.

\section{CONCLUSIONS}

In this paper we have proposed an approach to combine both the economic dispatch and emissions dispatch in a thermal power plant using the pareto optimal front of a multiobjective optimization problem. The results show that, by varying the weights of different objectives the optimum point of operation moves on a curve which is called as optimal front. It is the designer's choice to choose a point on the optimal front. The results also show that the two objectives that we considered in 
the problem, emissions and cost are contradictory. The betterment of one of them will worsen the other.

\section{REFERENCES}

[1] Prasanna.T.S , Somasundaram.P ,Fuzzy - Tabu Search Algorithm for combined economic and emission load dispatch, XXXII National Systems Conference, NSC 2008, December

[2] M.R Alrashidi, M.E El-Hawary, Impact of Loading Conditions on the Emission-Economic Dispatch, World Academy of Science, Engineering and Technology 39 2008.

[3] Y.Al-Kalaani, Power Plant Modelling Using on Line Emission Monitoring, Emirates Journal for Engineering Research, 9(1), 51-56 (2004).

[4] K.Sathish Kumar, V Tamil Selvan, N Murali, R Rajaram, N Shanmuga Sundaram, T Jayabarati, Economic Load Dispatch with Emission Constraints using various PSO Algorithms, WSEAS TRANSACTIONS on POWER SYSTEMS

[5] Po-Hung Chen, Hung-Cheng Chen, Chun-Liang Hsu, Genetic Algorithm based approach for Power Generation Dispatch with Emission Constraints.

[6] Subramanian Srikrishna, Ganeshan Sivarajan, Sequential Approach with Matrix Framework for Various Types of Economic Thermal Power Dispatch Problems, Energy and Power Engineering, 2010, 2, 111-121.

[7] Chao-Lung Chiang, Ji-Horng Liaw, Ching-Tzong Su, New approach with a genetic algorithm framework to multiobjective generation dispatch problems, European Transactions on Electrical Power; 15:381-395.

[8] Y.Labbi, D. Ben Attuos, Big Bang Big Crunch Optimization algorithm for economic dispatch with valvepoint effect, Journal of Theoretical and Applied Information Technology.

[9] Osman K. Erol, Ibrahim Eksin, A new optimization method : Big Bang-Big Crunch, Advances in Engineering Software 37 (2006) 106-111.

[10] Moacir Kripka, Rosana Maria Luvezute Kripka, "Big Crunch" Optimization method, International Journal on Engineering Optimization.

[11] P.Venkatesh, K.Y.Lee, "Multi-Objective Evolutionary Programming for Economic Emission Dispatch Problem",
Power and Energy Society General Meeting-Conversion and Delivery of Electrical Energy in the $21^{\text {st }}$ Century, 2008,pp.1-8.

[12] M.Basu, "A simulated annealing based goal attainment method for economic emission laod dispatch of fixed head hydrothermal power systems", Electrical Power and Energy Systems, 27, 2005, pp.147-153.

[13] L.Wang, C.Singh, "Reserve-constrained multiarea environmental / economic dispatch based on particle swarm optimization with local search", Engineering Applications of Artificial Intelligence, 22, 2009, pp.298-307.

[14] M.Basu, "Dynamic economic emission dispatch using nondominated sorting genetic algorithm-II", Electrical Power and Energy Systems, 30, 2008, pp.140-149.

[15] Hishashi Tamaki, Hajime Kita, and Shingenobu Kobayashi, Multiobjective Optimization by Genetic Algorithms: A Review. In Toshio Fukuda and Takeshi Furuhashi, editors, Proceedings of the 1996 International Conference on Evolutionary Computation, pages 517-522, Nagoya, Japan, 1996. IEEE.

[16] Carlos M.Fonseca and Peter J.Fleming. An Overview of Evolutionary Algorithms in Multiobejctive Optimization, Evoluitonary Computation, 3(1):1-16,Spring 1995.

[17] Carlos M.Fonseca and Peter J.Fleming. An Overview of evolutionary algorithms in multiobjective optimization. Technical Report, Department of Automatic Control and Systems Engineering, University of Sheffield, Sheffield, U.K,. 1994.

[18] M.Gen, K.Ida, and Y.Li. Solving bicriteria solid transportation problem with fuzzy numbers by genetic algorithm. International Journal of computers and Industrial Engineering, 29:537-543,1995.

[19] Mitsuo Gen and Runwei Cheng. Genetic Algorithm and Engineering Design. John Wiely and Sons, Inc., New York 1997.

[20] X. Yang and M.Gen. Evolutionary program for bicriterial transportation problem. In M. Gen and T. Kobayashi, editors, Proceedings of the $16^{\text {th }}$ International Conference on Computers and Industrial Engineering, pages 451-454, Ashikaga, Japan, 1994. 